\title{
Determinants of Acute Respiratory Infection Among Children in Ethiopia: A Multilevel Analysis from Ethiopian Demographic and Health Survey
}

This article was published in the following Dove Press journal: International Journal of General Medicine

\author{
Zelalem Alamrew Anteneh (iD) \\ Hamid Yimam Hassen (iD) ${ }^{2}$ \\ 'School of Public Health, College of \\ Medicine and Health Sciences, Bahir Dar \\ University, Bahir Dar, Ethiopia; \\ ${ }^{2}$ Department of Public Health, College of \\ Health Sciences, Mizan-Tepi University, \\ Mizan-Tepi, Ethiopia
}

Background: Acute respiratory infection (ARI) is one of the leading public health challenges among children in low- and middle-income countries. Child mortality due to ARI is disproportionately higher in African regions. In Ethiopia, an encouraging progress in the reduction of ARI was observed until 2010, however, since then the national prevalence is unchanged. There is limited information for the persistently higher prevalence of the infection. Therefore, the aim of this study was to determine regional variations and identify factors associated with the infection.

Methods: This study used data from the Ethiopian Demographic and Health Survey (EDHS) conducted in 2016. The analysis used information from 10,006 children. A twolevel logistic regression analysis was used to consider the cluster random effect.

Results: Out of 10,006 children included, $15.9 \%, 8.9 \%$, and $8.8 \%$ reported cough, short rapid breaths, and chest complaint respectively two weeks before the survey, making the overall prevalence of ARI 8.8\%. Children aged six to 11 years (adjusted odds ratio (AOR) $=1.466,95 \%$ CI: $1.143-1.881)$, and 12 to $23(\mathrm{AOR}=1.390$, 95\%CI: $1.109-1.742)$, small birth size $(\mathrm{AOR}=1.387,95 \% \mathrm{CI})$, and animal dung as cooking fuel $(\mathrm{AOR}=1.904,95 \% \mathrm{CI}$ : $1.152-3.146)$ are significantly associated with higher odds of ARI in the final multilevel modeling. The AOR $(95 \% \mathrm{CI})$ for ARI for differing levels of altitude were: 1000 to 2000, 1.805 (1.403-2.483); 2000 to $3000,1.882$ (1.427-2.483); above 3000, 2.24 (1.023-4.907).

Conclusion: ARI is still a significant public health problem in Ethiopia among children underfive, with a huge variation in the burden across the regional states. Age of children, birth size, household cooking fuel, and altitude above sea level were important variables. Therefore, regional governments, health-care workers and concerned organizations should give emphasis to minimize ARI and the consequences associated with the disease.

Keywords: acute respiratory infection, determinant, children, Ethiopia

\section{Introduction}

In low and middle-income countries, a substantial proportion of childhood deaths are attributed to easily preventable and treatable illnesses such as acute respiratory infection (ARI), diarrhea, and malaria. ${ }^{1,2}$ Globally, 5.4 million children under the age of five died in 2017 alone, and $73 \%$ of the deaths occurred in Africa (49\%) and South East Asia (24\%). The under-five mortality rate in the WHO African Region is $74 / 1000$ live births, nearly eight times higher than that in the WHO European Region 9/1000 live births. ${ }^{3}$ Under-five mortality in Ethiopia is 67/1000 live births based on the recent 2016 Ethiopian Demographic and Health Survey. ${ }^{4}$ Acute
Correspondence: Zelalem Alamrew Anteneh

Email kzolam@gmail.com
International Journal of General Medicine 2020:13 17-26 
respiratory infection is one of the leading causes of childhood diseases that often result in serious health complications and deaths among children under-five. ${ }^{5}$ According to the global burden of disease (GBD) report in 2017, a lower respiratory infection responsible for 704,000 deaths in children younger than five years. ${ }^{6}$ Acute respiratory infection is not only the cause of death but is also the leading causes of years of life lost due to premature mortality and one of the most frequent reasons for hospitalization. ${ }^{7}$

Evidence showed that children are the segments of the population more affected by ARIs than adults because of several reasons such as children breathe more rapidly, and their metabolic rate is higher. In addition, children's immune systems are not fully developed, so the incidence of respiratory infections is higher compared to adults. ${ }^{8}$

Studies showed that several factors have been affecting acute respiratory infection in children; sex disparity in children has an effect on the incidence of acute respiratory infections, recently conducted studies indicated that ARI was higher in boys than in girls. ${ }^{9,10}$ Type of housing, history of parental smoking, respiratory infection among family members and the nutritional status of children were shown to affect the incidence of ARI in children. ${ }^{10,11}$ Educational level of mothers is a significant predictor of ARI in children, children from a mother with primary or no education had a higher risk of acquiring ARI. ${ }^{12,13}$ It is also shown that the kind of cooking fuel used at the household influences the incidence of ARI in children. ${ }^{14-16}$ In Ethiopia, according to the Ethiopian demographic and health survey (EDHS), the prevalence of ARI in children under five years of age was $13 \%$ in 2005 , and the magnitude reduced to $7 \%$ in EDHS 2011, however, the prevalence remained $7 \%$ in EDHS 2016. Despite the persistent higher prevalence of ARI among children in Ethiopia, contributing factors for the disease were not well explored. In addition, few studies conducted in the country are pocket level small and fragmented types. There is limited information on the determinants of morbidity due to ARI in children under five at a national level. Therefore, this study seeks to determine regional variations and identify factors associated with ARI among children.

\section{Methods}

This study used data from the nationally representative, crosssectional Ethiopian Demographic and Health Survey (EDHS) conducted in 2016. ${ }^{4}$ EDHS consist of a sample of households obtained through a two-stage stratified sampling procedure. The EDHS 2016 used the Ethiopia Population and Housing
Census (PHC), which was conducted in 2007 by the Ethiopia Central Statistical Agency (CSA) as the sampling frame. In the first stage, the country was divided into a total of 645 Enumeration Areas (EAs, which are considered as the primary sampling units) (202 in urban and 443 in rural areas) were selected using probability proportional to the size technique. A household listing was carried out in all the selected EAs to use it as a sampling frame for the selection of households in the second stage.

In the second stage, an equal probability systematic sampling technique was employed to select 28 households per cluster using the household listing. All women aged 15-49 and all men age 15-59 who were either permanent residents of the selected households or visitors who stayed in the household the night before the survey were eligible to be interviewed. This analysis used information from 10,006 children under the age of five years born to women living in these households and who are alive.

Data on morbidity of children was assessed through interviewing the mothers if their child had diarrhea, fever, cough, short rapid breaths, and difficulty breathing that is chest related in the two weeks preceding the survey. In this analysis we considered ARI symptoms include cough accompanied by (1) short, rapid breathing that is chestrelated, and/or (2) difficulty breathing that is chest-related.

Anemia measurement: blood specimens were collected from children aged 6-59 months for whom consent was obtained from their parents or other adults responsible for them. Blood samples were drawn from a drop of blood taken from a finger prick (or a heel prick in the case of children aged 6-11 months) and collected in a microcuvette. Hemoglobin analysis was carried out on-site using a battery-operated portable HemoCue analyser. For our analysis, based on the WHO hemoglobin level cut off points, hemoglobin level less than $7 \mathrm{~g} / \mathrm{dL}$ of blood is anemic otherwise normal. ${ }^{17}$

\section{Wealth Index Measurement}

It is a measure of socioeconomic status (SES) of the households to indicate inequalities in the society. The households were given scores based on assets (television, bicycle/car, size of agricultural land, quantity of livestock), and dwelling characteristics (sources of drinking water, sanitation facilities, and materials used for constructing houses) using principal component analysis (PCA), and the scores were compiled into five categories of wealth quintile (poorest, poorer, medium, richer, and richest) each comprising $20 \%$ of the population. ${ }^{4}$ 


\section{Data Analysis}

We chose relevant factors associated with incidence of acute respiratory infection through reviewing previous research and discussion of the researchers. We used some variables for analysis based on the original coding as it appears in the EDHS. However, several variables were obtained by computing from two or more variables, or by recoding the levels of individual variables. The variable toilet facility was recoded to no facility, not improved, and improved with various combinations. Similarly, the variable water source was created as per WHO recommendation as improved and not improved. Type of cooking fuels was categorized as electricity and gas, kerosene, charcoal, wood, straw and agricultural products, and animal dung. The EDHS 2016 data contain an indicator of household wealth status constructed by combining variables related to ownership of household items, dwelling characteristics and construction materials of the unit in which the household lives. A total of 21 and 13 variables were included in the bivariate and multivariate analysis respectively. A twolevel logistic regression was used, a model which is most appropriate to consider the cluster random effect in a multivariate setting. ${ }^{18}$ The main reason to apply multilevel modeling was the data collected have a hierarchical or clustered structure. The first level represents the individual and household and the second level factor is the clusters. Analysis on the data was performed using STATA (Computing Resource Center, Berkeley, CA, USA). Variables with $p$-values less than 0.05 during multivariate analysis was considered statistically significant.

\section{Results}

\section{Sociodemographic Characteristics of Mothers}

A total of 10,006 mother-child pairs were included in our analysis, 2414 (24\%) of mothers of children under five were less than 24 years of age, and of these women, 9518 (95.1\%) of them were in a marital relationship during the time of the survey. More than three in five women have no formal education, only $1706(11.8 \%)$ of them reported to have secondary and above. It is also shown that $8099(80.9 \%)$ of women were rural residents, and 1954 (19.5\%) had three or more children under five years in their household. About $3706(37 \%)$ and $1670(16.7 \%)$ of the respondents were in the poorest and poorer wealth quantification categories respectively. More than $85 \%$ of the respondents use wood and agricultural products as a source of cooking fuel, only
$4.9 \%$ of the respondents has access to electricity and gas. Regarding water source and basic sanitation facility, 5972 (60.4\%) of the respondents had improved water source, and only $1748(17.7 \%)$ of the respondents had improved toilet facility, while 4355 (44.1\%) of the respondents had no toilet facility at all. Two-fifths (20.4\%) of women had exposure to at least one type of media, $1196(12 \%)$ to the radio, 1301 $(13 \%)$ to TV, and $179(1.8 \%)$ to magazine (Table 1).

\section{Sociodemographic, Birth History and Physical Measurements of Children}

Of the children included in the study, 1093 (11.3\%) were less than six months of age, 2923 (30.1\%) were between six and 24 months and the remaining 5680 (58.6\%) were between 24 and 59 months of age. The proportion of male and female children were nearly equal ( $51 \%$ vs $49 \%$ ) respectively. This study shows that $2031(20.3 \%)$ of children were first births, and $3562(35.6 \%)$ were the fifth and above births for the mother. Of the non-first births, $1052(10.5 \%)$ were born within 18 months of an older sibling, and $862(8.6 \%)$ were born within 18-23 months. Regarding growth and nutritional status of children, $2281(25.3 \%)$ of children were underweight, $3223(36.4 \%)$ were stunted, 1080 (12.1\%) were wasted, and $7795(60.2 \%)$ were anemic. The study also showed that $5425(54.2 \%)$ and $1176(11.8 \%)$ of the children received vitamin A supplementation and drugs against intestinal parasites respectively, in the last six months before the survey, and 713 (7.1\%) of children received iron pills in the last seven days before the survey (Table 2).

\section{Morbidity Status of Children}

Morbidity assessment indicated, 1586 (15.9\%), 891 $(8.9 \%)$, and $884(8.8 \%)$ of children reported to have had cough, short rapid breaths and chest complaint respectively two weeks before the survey. Overall, 885 (8.8\%) of children had acute respiratory infection two weeks before the survey. However, 1354 (13.5\%) and 1090 $(10.9 \%)$ of children had fever and diarrhea. One-fourth (25.9\%) them reported to have had at least one childhood disease; of those with the disease more than half (57.6\%) had multiple morbidities (Table 3).

\section{Regional Distribution of Childhood Morbidities}

This study indicates there are huge disparities in the distributions of childhood diseases across the different regional states of Ethiopia. The burden of diarrheal diseases was 123(13.3\%) 
Table I Sociodemographic Characteristics of the Respondent/ Household

\begin{tabular}{|c|c|c|c|}
\hline Variable & Categories & Frequency & Percentage \\
\hline \multirow[t]{4}{*}{ Age of mother } & $15-24$ & 2414 & 24.1 \\
\hline & $25-29$ & 2978 & 29.8 \\
\hline & $30-34$ & 2238 & 22.4 \\
\hline & $35-49$ & 2376 & 23.7 \\
\hline \multirow[t]{4}{*}{ Marital status } & Never married & 59 & 0.6 \\
\hline & Married & 9518 & 95.1 \\
\hline & Widowed & 125 & 1.2 \\
\hline & Divorced & 304 & 3.0 \\
\hline \multirow{4}{*}{$\begin{array}{l}\text { Highest education of } \\
\text { mother }\end{array}$} & No education & 6387 & 63.8 \\
\hline & Primary & 2538 & 25.4 \\
\hline & Secondary & 697 & 7.0 \\
\hline & Higher & 384 & 3.8 \\
\hline \multirow{5}{*}{$\begin{array}{l}\text { Father's educational } \\
\text { level }\end{array}$} & No education & 4604 & 48.9 \\
\hline & Primary & 3034 & 32.2 \\
\hline & Secondary & 972 & 10.3 \\
\hline & Higher & 734 & 7.8 \\
\hline & Do not know & 73 & 0.8 \\
\hline \multirow[t]{6}{*}{ Religion } & Muslim & 5068 & 50.6 \\
\hline & Orthodox & 2944 & 29.4 \\
\hline & Protestant & 1761 & 17.6 \\
\hline & Catholic & 61 & 0.6 \\
\hline & Traditional & 96 & 1.0 \\
\hline & Other & 76 & 0.8 \\
\hline \multirow[t]{2}{*}{ Place of residence } & Urban & 1907 & 19.1 \\
\hline & Rural & 8099 & 80.9 \\
\hline \multirow{3}{*}{$\begin{array}{l}\text { Number of children } \\
\text { under five }\end{array}$} & At most one & 3677 & 36.7 \\
\hline & Two & 4375 & 43.7 \\
\hline & Three and above & 1954 & 19.5 \\
\hline \multirow[t]{5}{*}{ Wealth index } & Poorest & 3706 & 37.0 \\
\hline & Poorer & 1670 & 16.7 \\
\hline & Middle & 1386 & 13.9 \\
\hline & Richer & 1227 & 12.3 \\
\hline & Richest & 2017 & 20.2 \\
\hline \multirow{6}{*}{$\begin{array}{l}\text { Cooking fuel } \\
(n=9884)\end{array}$} & Electricity and gas & 518 & 5.2 \\
\hline & Kerosene & 37 & 0.4 \\
\hline & Charcoal & 896 & 9.1 \\
\hline & Wood, straw & 8111 & 82.1 \\
\hline & Animal dung & 319 & 3.2 \\
\hline & Others & 3 & 0.0 \\
\hline \multirow[t]{3}{*}{ Type of toilet facility } & No facility & 4355 & 44.1 \\
\hline & Not improved & 3781 & 38.3 \\
\hline & Improved & 1748 & 17.7 \\
\hline \multirow[t]{2}{*}{ Water source } & Unimproved & 3912 & 39.6 \\
\hline & Improved & 5972 & 60.4 \\
\hline \multirow[t]{2}{*}{ Smoke cigarettes } & No & 9913 & 99.1 \\
\hline & Yes & 93 & 0.9 \\
\hline
\end{tabular}

(Continued)
Table I (Continued).

\begin{tabular}{|l|l|l|l|}
\hline Variable & Categories & Frequency & Percentage \\
\hline Media exposure & No & 7964 & 79.6 \\
& Yes & 1960 & 20.4 \\
\hline Radio & No & 8810 & 88.0 \\
& Yes & 1196 & 12.0 \\
\hline Magazine & No & 9827 & 98.2 \\
& Yes & 179 & 1.8 \\
\hline TV & No & 8705 & 87.0 \\
& Yes & 1301 & 13.0 \\
\hline
\end{tabular}

in the Amhara region, and the magnitude was $125(12.6 \%)$ among children in Tigray regional state. The highest and lowest percentages of cough was observed in Tigray and Benishangul regions, where, 302(30.4\%) and 41(5\%) of children in the regions reported cough respectively. Similarly, the burden of shortness of breath was the highest Tigray region with the prevalence of 161(16.2\%) and lowest in Benishangul regional state with prevalence of $21(2.6 \%)$. The overall magnitude of acute respiratory infection was highest in Tigray region with 167(16.8\%), followed by Addis Ababa 51 (11.4\%) and Oromia 157(10.5\%) regional states (Table 4). The Maps of Ethiopia containing regional states of the country are shown in Figure 1.

\section{Factors Associated with Acute Respiratory Infection Among Under-Five Children}

In bivariate logistic regression analysis, sex, age, birth size, twin status, stunting, underweight, reading magazines, maternal educational level, place of residence, cooking fuel, toilet facility, and altitude were showed association with acute respiratory infection at $20 \%$ level of significance. However, only age of children, birth size, cooking fuel, and altitude were appeared significant in the final multilevel modeling.

The multivariate analysis showed, children aged between 6 to 11 months and 12 to 23 months were about $50 \%$ at higher odds of acquiring acute respiratory infection as compared to those less than 6 months $(\mathrm{AOR}=1.466$, 95\% CI: $1.143,1.881$, and AOR $=1.390,95 \%$ CI: 95\% CI: $1.109,1.742)$. While, children aged between 48 to 59 months were $27 \%$ less likely to be affected with an acute respiratory infection as compared to children with less than 6 months of age $(\mathrm{AOR}=0.727,95 \% \mathrm{CI}: 0.571$, $0.925)$. Children of smaller size at births have $38 \%$ higher 
Table 2 Sociodemographic Characteristics of Children less than 59 Months of Age in Ethiopia

\begin{tabular}{|c|c|c|c|}
\hline Variable & Categories & Frequency & Percentage \\
\hline \multirow[t]{3}{*}{ Age in months } & Less than 6 & 1093 & 11.3 \\
\hline & 6 to 24 & 2923 & 30.1 \\
\hline & 24 and above & 5680 & 58.6 \\
\hline \multirow[t]{2}{*}{ Sex } & Male & 5107 & 51.0 \\
\hline & Female & 4899 & 49.0 \\
\hline \multirow[t]{4}{*}{ Birth order } & First & 2031 & 20.3 \\
\hline & Second & 1706 & 17.0 \\
\hline & 3 to 4 & 2707 & 27.1 \\
\hline & 5 and above & 3562 & 35.6 \\
\hline \multirow[t]{3}{*}{ Succeeding } & Last & 7012 & 70.1 \\
\hline & $<20$ & 632 & 6.3 \\
\hline & $20+$ & 2362 & 23.6 \\
\hline \multirow[t]{5}{*}{ Preceding } & First born & 2040 & 20.4 \\
\hline & $<18$ months & 1052 & 10.5 \\
\hline & 18 to 23 months & 862 & 8.6 \\
\hline & 24 to 35 months & 2550 & 25.5 \\
\hline & 36 and above & 3502 & 35.0 \\
\hline \multirow[t]{3}{*}{ Twin } & Single birth & 9786 & 97.8 \\
\hline & Ist of multiple & 116 & 1.2 \\
\hline & 2nd of multiple & 104 & 1.0 \\
\hline \multirow[t]{4}{*}{ Anaemia } & Severe & 311 & 4.0 \\
\hline & Moderate & 2531 & 32.5 \\
\hline & Mild & 1849 & 23.7 \\
\hline & Not anemic & 3104 & 39.8 \\
\hline \multirow[t]{2}{*}{ Underweight } & Yes & 2281 & 25.3 \\
\hline & No & 6752 & 74.7 \\
\hline \multirow[t]{2}{*}{ Stunting } & Yes & 3223 & 36.4 \\
\hline & No & 5632 & 63.6 \\
\hline \multirow[t]{2}{*}{ Wasting } & Yes & 1080 & 12.1 \\
\hline & No & 7839 & 87.9 \\
\hline \multirow{3}{*}{$\begin{array}{l}\text { Size at birth } \\
(n=9905)\end{array}$} & Large & 3021 & 30.5 \\
\hline & Average & 4196 & 42.4 \\
\hline & Small & 2688 & 27.1 \\
\hline \multirow{2}{*}{$\begin{array}{l}\text { Vitamin A last } 6 \\
\text { months }(n=9805)\end{array}$} & No & 4380 & 44.7 \\
\hline & Yes & 5425 & 55.3 \\
\hline \multirow{2}{*}{$\begin{array}{l}\text { Drugs for IP last } 6 \\
\text { months ( } n=9808)\end{array}$} & No & 8632 & 88.0 \\
\hline & Yes & 1176 & 12.0 \\
\hline Taking iron pills last & No & 9125 & 92.8 \\
\hline 7 days $(n=9838)$ & Yes & 713 & 7.2 \\
\hline
\end{tabular}

odds of having an acute respiratory infection as compared to children with average birth size, $(\mathrm{AOR}=1.387,95 \% \mathrm{CI}$ : $1.198,1.605)$.

Children from households who used animal dung as a source of cooking fuel had $90 \%$ higher odds of developing
Table 3 Frequency of Childhood Morbidities in Children less than 59 Months of Age in Ethiopia

\begin{tabular}{|l|l|l|l|}
\hline Symptoms & Presence & Frequency & Percent \\
\hline Cough & No & 8337 & 83.3 \\
& Yes, last two weeks & 1586 & 15.9 \\
& Do not know & 83 & 0.8 \\
\hline Short rapid & No & 9028 & 90.2 \\
breaths & Yes & 891 & 8.9 \\
& Do not know & 87 & 0.9 \\
\hline Chest & No & 9115 & 91.1 \\
complaint & Yes & 884 & 8.8 \\
& Do not know & 7 & 0.1 \\
\hline Over all ARI & Yes & 885 & 8.8 \\
& No & 9121 & 91.2 \\
\hline Fever & No & 8564 & 85.6 \\
& Yes & 1354 & 13.5 \\
& Do not know & 88 & 0.9 \\
\hline Diarrhea & No & 8826 & 88.2 \\
& Yes, last two weeks & 1090 & 10.9 \\
& Do not know & 90 & 0.9 \\
\hline Morbidity & No morbidity & 7417 & 74.1 \\
combined & One morbidity & 1097 & 11.0 \\
& Multiple morbidity & 1492 & 14.9 \\
\hline
\end{tabular}

Abbreviation: ARI, acute respiratory infections.

acute respiratory infection as compared to children of households who use electricity $(\mathrm{AOR}=1.904,95 \%$ CI:1.152, 3.146). In this study there is a strong association between acute respiratory infection and altitude level; children from 1000 to 2000,2000 to 3000 and greater than 3000 meters had $1.81,1.89$, and 2.24 times higher risk of developing acute respiratory infection compared to children from low altitude (less than 1000 meters) (AOR $=1.805,95 \%$ CI: 1.403, 2.322, $\mathrm{AOR}=1.882,95 \% \mathrm{CI}: 1.427,2.483, \& \mathrm{AOR}=2.241,95 \%$ CI: $1.023,4.907)$ respectively (Table 5).

\section{Discussions}

According to the WHO 2017 report, ARIs are among the leading causes of childhood diseases that often result in serious health complications and deaths in children under five years of age. ${ }^{19}$ The Sustainable Development Goal (SDG) target 3.2 aimed, by 2030, to end preventable deaths of newborns and children under five years of age, with all countries aiming to reduce under-five mortality to at least as low as 25 per 1000 live births. ${ }^{20}$ As part of the implementation, prevention of ARIs is considered an effective strategy. This study aimed at determining the 
Table 4 Frequency Distributions of Childhood Morbidities across Regions in Ethiopia

\begin{tabular}{|l|l|l|l|l|l|}
\hline \multirow{2}{*}{ Region } & \multicolumn{4}{l|}{ Morbidity in the Last Two Weeks } & \multicolumn{2}{l|}{ ARI Combined N (\%) } \\
\cline { 2 - 6 } & Cough N (\%) & Fever N (\%) & $\begin{array}{l}\text { Shortness of } \\
\text { Breath N (\%) }\end{array}$ & Chest N (\%) & $167(16.8)$ \\
\hline Tigray & $302(30.4)$ & $234(23.6)$ & $161(16.2)$ & $161(16.2)$ & $95(9.8)$ \\
Afar & $163(16.8)$ & $152(15.6)$ & $72(7.4)$ & $71(7.3)$ & $77(8.3)$ \\
Amhara & $158(17.0)$ & $113(12.2)$ & $109(11.7)$ & $107(11.5)$ & $157(10.5)$ \\
Oromia & $347(23.2)$ & $221(14.8)$ & $224(15.0)$ & $224(15.0)$ & $81(5.8)$ \\
Somali & $125(8.9)$ & $114(8.1)$ & $66(4.7)$ & $66(4.7)$ & $26(3.2)$ \\
Benishangul & $41(5.0)$ & $59(7.2)$ & $21(2.6)$ & $20(2.5)$ & $112(9.3)$ \\
SNNPR & $211(17.5)$ & $188(15.6)$ & $121(10.0)$ & $120(10.0)$ & $41(6.1)$ \\
Gambela & $55(8.2)$ & $95(14.2)$ & $40(6.0)$ & $40(6.0)$ & $30(5.3)$ \\
Harari & $41(7.3)$ & $53(9.4)$ & $17(3.0)$ & $17(3.0)$ & $51(11.4)$ \\
Addis Ababa & $68(15.2)$ & $66(14.8)$ & $29(6.5)$ & $31(6.0)$ & $48(9.3)$ \\
Dire Dawa & $75(14.5)$ & $59(11.4)$ & $31(6.0)$ & $884(8.8)$ & $885(8.8)$ \\
Total & $1586(15.9)$ & $1354(13.5)$ & $891(8.9)$ & \\
\hline
\end{tabular}

cross-regional variations and identifying the determinant factors of ARIs among children under five years of age in Ethiopia.

The study found that $8.8 \%$ of children under five years have reported history of ARI two weeks before the survey.
Despite various efforts made to prevent childhood diseases in Ethiopia, the prevalence has persisted since 2011. ${ }^{4,21}$ Our findings showed that there is a huge disparity in the distribution of ARIs in children across the different regional states of Ethiopia. The highest prevalence of ARI, 16.8\%,

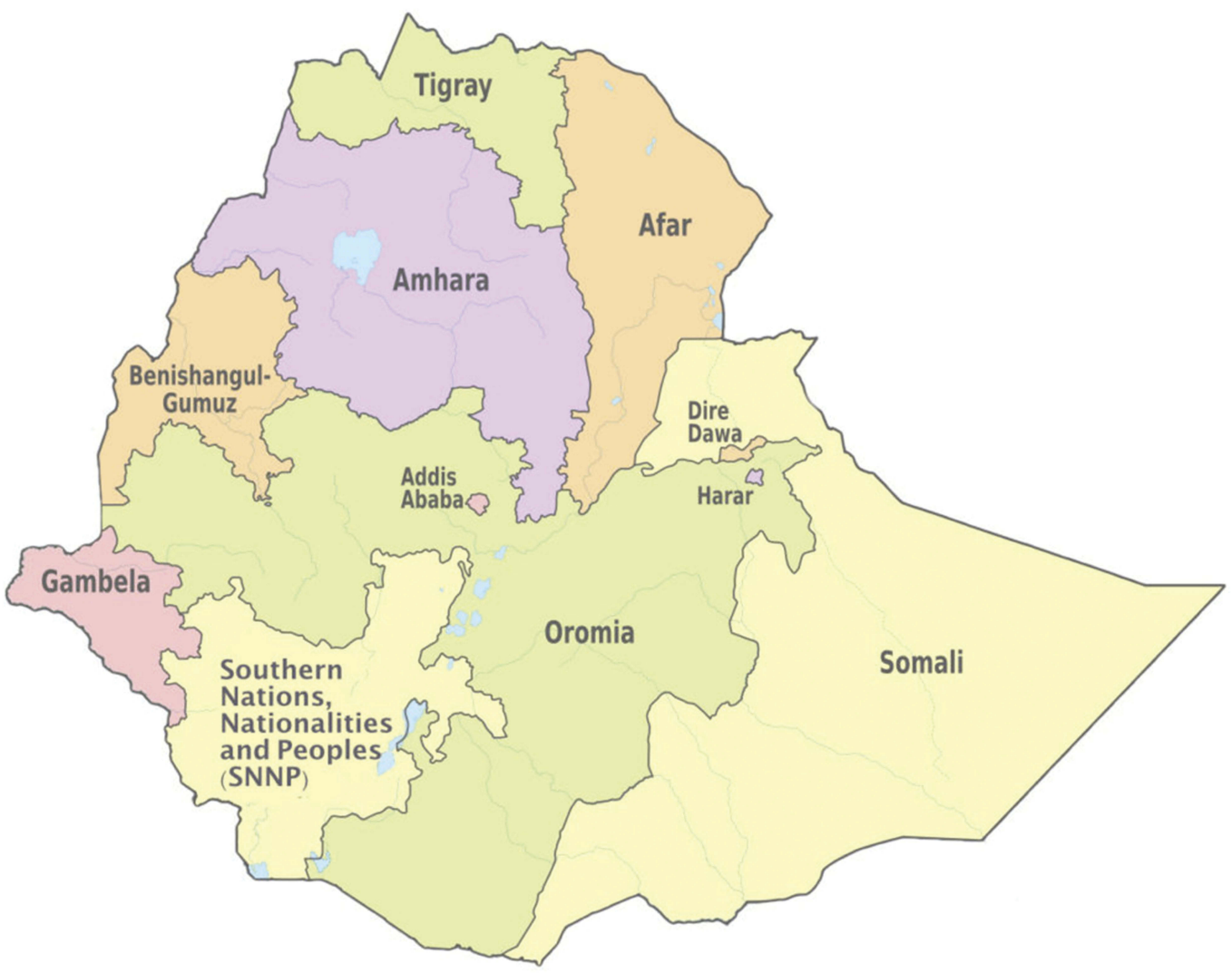

Figure I The maps of regional states in Ethiopia. Image courtesy with permission from https://www.ethiovisit.com/addis-ababa/65/. 
Table 5 Association between Acute Respiratory Infection and Predictor Variables among Children under five in Ethiopia

\begin{tabular}{|c|c|c|c|}
\hline Variables & Levels & COR & AOR \\
\hline Sex & $\begin{array}{l}\text { Boy } \\
\text { Girl }\end{array}$ & $\begin{array}{l}\text { I } \\
0.980(0.883-1.088)\end{array}$ & $\begin{array}{l}\text { I } \\
0.994(0.883-1.119)\end{array}$ \\
\hline Child age (months) & $\begin{array}{l}<6 \\
6-11 \\
12-23 \\
24-35 \\
36-47 \\
48-59\end{array}$ & $\begin{array}{l}\mathrm{I} .502(\mathrm{I} .206-\mathrm{I} .872) \\
\mathrm{I} .4 \mathrm{I} 0(\mathrm{I} .160-\mathrm{I} .7 \mathrm{I}) \\
\mathrm{I} .168(0.957-\mathrm{I} .426) \\
0.973(0.794-1.193 \\
0.708(0.574-0.873)\end{array}$ & $\begin{array}{l}\text { I } \\
\text { I. } 466(1.143-1.88 I) * \\
1.390(1.109-1.742) * \\
1.238(0.982-1.561) \\
0.980(0.773-1.242) \\
0.727(0.571-0.925) *\end{array}$ \\
\hline Birth size & $\begin{array}{l}\text { Average } \\
\text { Smaller } \\
\text { Larger }\end{array}$ & $\begin{array}{l}1.340(1.181-1.520) \\
1.036(0.911-1.177)\end{array}$ & $\begin{array}{l}\text { I } \\
\text { I.387 (I.I98-I.605)* } \\
\text { I.I } 44(0.988-I .323)\end{array}$ \\
\hline Child is twin & $\begin{array}{l}\text { Single birth } \\
\text { Ist of multiple } \\
\text { 2nd of multiple }\end{array}$ & $\begin{array}{l}1.096(0.681-1.763) \\
0.968(0.574-1.633)\end{array}$ & $\begin{array}{l}\text { I } \\
0.977(0.57|-| .670) \\
0.930(0.5 \text { I } 9-1.668)\end{array}$ \\
\hline Stunting & $\begin{array}{l}\text { No } \\
\text { Yes }\end{array}$ & $0.930(0.83 \mid-1.042)$ & $\begin{array}{l}\text { I } \\
0.941(0.814-1.088)\end{array}$ \\
\hline Underweight & $\begin{array}{l}\text { No } \\
\text { Yes }\end{array}$ & 0.991 (0.875-I.I22) & $\begin{array}{l}\text { I } \\
0.955(0.815-1.119)\end{array}$ \\
\hline Read magazine & $\begin{array}{l}\text { No } \\
\text { Yes }\end{array}$ & & $\begin{array}{l}\text { I } \\
0.675(0.399-1.142)\end{array}$ \\
\hline Education of mother & $\begin{array}{l}\text { No education } \\
\text { Primary } \\
\text { Secondary } \\
\text { Higher }\end{array}$ & $\begin{array}{l}1.216(1.080-1.370) \\
0.90 I(0.724-1.121) \\
0.769(0.567-1.042)\end{array}$ & $\begin{array}{l}\text { I } \\
1.18(1.02-1.36) \\
1.00(0.76-1.33) \\
0.95(0.62-1.45)\end{array}$ \\
\hline Place of residence & $\begin{array}{l}\text { Urban } \\
\text { Rural }\end{array}$ & $1.151(1.003-1.320)$ & $\begin{array}{l}\text { I } \\
0.93 \text { I (0.689-1.259) }\end{array}$ \\
\hline Cooking fuel & $\begin{array}{l}\text { Electric and gas } \\
\text { Kerosene } \\
\text { Charcoal } \\
\text { Wood, straw } \\
\text { Animal dung } \\
\text { Others }\end{array}$ & $\begin{array}{l}0.807(0.306-2.123) \\
0.957(0.7 \mid 2-1.285) \\
1.031(0.810-1.311) \\
1.565(1.100-2.213) \\
0\end{array}$ & $\begin{array}{l}\text { I } \\
0.802(0.244-2.64) \\
\text { I.0I (0.697-I.464) } \\
\text { I.267 (0.869-I.848) } \\
\text { I.904 (I.I52-3.I46)* } \\
0\end{array}$ \\
\hline Toilet facility & $\begin{array}{l}\text { No facility } \\
\text { Not improved } \\
\text { Improved }\end{array}$ & $\begin{array}{l}\text { I } \\
\text { I.024 (0.9II-I.I50) } \\
0.985(0.848-I .144)\end{array}$ & $\begin{array}{l}\text { I } \\
0.908(0.775-1.063) \\
\text { I.047 (0.830-I.322) }\end{array}$ \\
\hline Altitude (meters) & $\begin{array}{l}<1000 \\
1000-1999 \\
2000-2999 \\
\geq 3000\end{array}$ & $\begin{array}{l}\text { I } \\
\text { I.70I (I.468-I.970) } \\
\text { I.780 (I.5I5-2.090) } \\
\text { I.885 (I.205-2.950) }\end{array}$ & $\begin{array}{l}\text { I } \\
\text { I.805 (I.403-2.322)* } \\
\text { I.882 ( } 1.427-2.483)^{*} \\
2.24 \mathrm{I}(1.023-4.907)^{*}\end{array}$ \\
\hline
\end{tabular}

Notes: *Statistically significant at $p$-value of $0.05(95 \% \mathrm{Cl}$ not including I)

Abbreviations: $\mathrm{CO}$, crude odds ratio; $\mathrm{AOR}$, adjusted odds ratio.

occurred in Tigray and the lowest, $3.2 \%$, in BenishangulGumuz region. There could be several reasons for the regional variations in the disease distributions including environmental, climatic, and infrastructure difference across the regions. In addition, the difference in the altitude of the regions in Ethiopia could contribute to the difference in ARI. This study indicated that the age of children was a significant predictor of acquiring an ARI, where children 
aged between six and 11, and 12 and 23 months had about $50 \%$ and $40 \%$ higher risk of ARI respectively compared to children less than six months. However, children aged 48 months and above had $27 \%$ less chance of getting an ARI compared to children aged less than six months. This could be due to the introduction of complementary feeding at the sixth month and increasing child mobility, which likely increases exposure to microbes and other risk factors. ${ }^{22,23}$ However, as the age of children increases beyond 48 months the risk of ARI decreases, which could be due to maturation of immunity and adaptation to infectious agents. ${ }^{24,25}$ Our finding is in line with a study conducted in the Democratic Republic of Congo where the risk of the ARI increased in the first 8-20 months after birth but improved gradually thereafter. ${ }^{26}$

In our study children who were smaller at birth were more likely to report an ARI compared to children with average birth size, where smaller sized children had a $38 \%$ higher chance of developing an $\mathrm{ARI}(\mathrm{AOR}=1.387,95 \% \mathrm{CI}$ : $1.198-1.605)$. This finding is consistent with a study conducted by Atul Choube et al in India, where significantly higher prevalence of ARI was observed among children having low birth weight. ${ }^{27}$ The lower concentrations of interleukin 7 in plasma, and shorter telomere length in peripheral blood mononuclear cells among low birth weight children could increase the susceptibility to several infectious agents including acute respiratory infections. ${ }^{28-32}$

Household cooking fuel was found to affect ARI, children from households who use animal dung as a source of cooking fuel had a $90 \%$ higher risk of developing ARI compared to children from households who use electricity. Several studies support our finding, a study conducted in northwest Ethiopia revealed that children from households using wood, dung, or straw as a cooking fuel have a threefold higher risk of suffering from ARI compared to children from households using electricity. ${ }^{33}$ Similarly, a study done in Addis Ababa and Pakistan showed, the use of biomass fuels including animal dung for cooking exposes children to the risk of ARI. ${ }^{34-36}$ This may be due to children exposed to cooking smoke coming from the combustion of the biomass, consequently leading to an ARI. ${ }^{37}$

In our study, there is a strong association between altitude and odds of getting an ARI in children; the disease revealed a trend of rising following increasing altitude level. Children living in the altitudes between 1000 and 2000, 2000 and 3000 , and greater than 3000 meters had 1.81, 1.89, and 2.24 times higher risk of developing ARI compared to children from lower altitudes (less than 1000 meters). In the context of Ethiopia, electricity is accessible to very few households particularly in the urban areas, there is no access for the rural community to get cleaner cooking fuels. People often use wood, animal dung, straw, and other organic materials as a source of fuel to cook food. Especially people living at the higher altitude use biomass fuels both for cooking and heating their houses, these smoky wood stoves may lead children to be exposed to the smoke that might result in ARIs. In addition, several studies confirm that respiratory infection is a common health problem at high altitude compared to the lowlands. ${ }^{38-40}$

The use of data with large sample size and considering several explanatory variables make this study appealing. Moreover, the use of multilevel analysis is another strength of this study. Despite its strength, these findings should be interpreted considering the following limitations. First, the cross-sectional nature of the source data, does not let us measure seasonal variations in disease episodes or the impact on the results of this study. Second, our estimates on incidence of ARIs are based on women's self-report based on illness perception of the mothers could introduce bias. Third, the birth size of children is taken from subjective report of the mothers, which could have result bias. Nevertheless, these biases are nondifferential, as they are independent of the characteristics of the women or of their children.

\section{Conclusions}

Based on the findings our study, there is a huge regional disparity in the magnitude of ARI in children across the regions in Ethiopia; children in Tigray region were disproportionally more affected than any other regions in the country. The prevalence of ARI in Tigray region is nearly twice the national average. Therefore, the regional government, regional health bureaus, and other concerned organizations need to see and evaluate their activities in the to minimize the prevalence of ARI and similar childhood illnesses. The risk of getting ARI from the time of initiation of complementary food up to 24 months of age is much higher than the risk before six months, however, gradually the risk decreases from the age of 24 months onwards. The families, health-care workers and program planners on child health care should give emphasis to this critical period to reduce the risk of childhood diseases. Children with smaller birth size were more likely to report ARI, therefore, specifically, these highly vulnerable children should receive special attention in the health-care 
system to minimize child mortality from ARI and its complications. Household cooking fuel is the other variable that showed significant association with ARI.The regional health offices should work on awareness to minimize exposure to smoke to prevent ARI. In addition, government and concerned organizations should work to access alternative clean cooking fuel sources. Children from households from a higher altitude above sea level should receive prior attention as they are more affected compared to their counterparts.

\section{Ethics Approval and Consent to Participate}

The data for this study was received from the DHS office upon request. The data was collected by Ethiopian Central Statistical Agency (CSA) and Federal Ministry of Health (FMoH) by technical assistance of ICF through the DHS Program. The ethical clearance was provided by the Federal Democratic Republic of Ethiopia Ministry of Science and Technology and the Institutional Review Board of ICF International. Written consent to participate in the study was obtained from parents and the data were recorded anonymously.

\section{Data Sharing Statement}

The study used the Ethiopian Demographic and Health Survey 2016. The data is available and can be obtained from the DHS (https://dhsprogram.com/Data/) upon request.

\section{Acknowledgments}

We acknowledge the Demographic and Health Survey program for providing us with the data. We extend our acknowledgement to the Ethiopian Demographic and Health Survey team and participants in 2016.

\section{Author Contributions}

All authors made substantial contributions to conception and design, acquisition of data, or analysis and interpretation of data; took part in drafting the article or revising it critically for important intellectual content; gave final approval of the version to be published; and agree to be accountable for all aspects of the work.

\section{Disclosure}

The authors report no conflicts of interest in this work.

\section{References}

1. Daniel E, Roth LEC, Ezzati M, Black RE. Acute lower respiratory infections in childhood: opportunities for reducing the global burden through nutritional interventions. Bull World Health Organ. 2008;86 (5):356-364. doi:10.2471/BLT.07.049114

2. UNICEF. Inter agency working group on community integrated management of childhood illness. 2008; Available from: https:// www.unicef.org/programme/cimci/. Accessed February 2, 2019.

3. World Health Organization. World health Statistics. 2010; Available form: www.who.int/gho/publications/world_health_statistics/EN WHS10_Full.pdf. Accessed February 2, 2019.

4. Central Statistical Agency Addis Ababa and The DHS Program ICF Rockville, Maryland, USA. Ethiopian Demographic and Health Survey 2016. Central Statistical Agency (CSA): Ethiopia; 2017.

5. World Health Organization. Children: reducing mortality. 2018; Available from: https://www.who.int/news-room/fact-sheets/detail/ children-reducing-mortality. Accessed February 4, 2019.

6. Christopher Troeger MF PCRea. Estimates of the global, regional, and national morbidity, mortality, and aetiologies of lower respiratory tract infections in 195 countries: a systematic analysis for the Global Burden of Disease Study 2015. Lancet Infect Dis. 2017;17(11): P1133-P1161. doi:10.1016/S1473-3099(17)30396-1

7. Lozano R, Foreman K. Global and regional mortality from 235 causes of death for 20 age groups in 1990 and 2010: a systematic analysis for the Global Burden of Disease Study 2010. Lancet Infect Dis. 2012;380(9859):2095-2128.

8. European Respiratory Society. Respiratory disease in adults and children. Chronic respiratory disease in children. 2019; Available form: https://www.erswhitebook.org/chapters/outdoor-environment/respira tory-disease-in-adults-and-children/. Accessed February 4, 2019.

9. Nair H, Rudan I, Simões EA, et al. Global and regional burden of hospital admissions for severe acute lower respiratory infections in young children in 2010: a systematic analysis. Lancet. 2013;38 (9875):1380-1390. doi:10.1016/S0140-6736(12)61901-1

10. Savitha AK. Determinants of acute respiratory infections among under five children in a rural area of Tamil Nadu, India. J Family Med Prim Care. 2018;7(6):1268-1273. doi:10.4103/jfmpc.jfmpc_131_18

11. Tazinya AA, Halle-Ekane GE, Mbuagbaw LT. et al. Risk factors for acute respiratory infections in children under five years attending the Bamenda Regional Hospital in Cameroon. BMC Pulm Med. 2018;18 (7). doi:10.1186/s12890-018-0579-7

12. Tazinya AA, Mbuagbaw LT, Abanda M, Atashili J, Obama MT. Risk factors for acute respiratory infections in children under five years attending the Bamenda Regional Hospital in Cameroon. BMC Pulm Med. 2018;18(1):7. doi:10.1186/s12890-018-0579-7

13. Geberetsadik A, Berhane Y. Factors associated with acute respiratory infection in children under the age of 5 years: evidence from the 2011 ethiopia demographic and health survey. Pediatric Health Med Ther. 2015;6(1):9-13. doi:10.2147/PHMT.S77915

14. Naz S, Agho KE. Household air pollution from use of cooking fuel and under-five mortality: the role of breastfeeding status and kitchen location in Pakistan. PLoS One. 2017;12(3):e0173256. doi:10.1371/ journal.pone. 0173256

15. Langbein J. Firewood, smoke and respiratory diseases in developing countries - the neglected role of outdoor cooking. PLoS One. 2017;12(6):e0178631. doi:10.1371/journal.pone.0178631

16. Amha Admasie AK, Worku A. Children under five from houses of unclean fuel sources and poorly ventilated houses have higher odds of suffering from acute respiratory infection in Wolaita-Sodo, Southern Ethiopia: a Case-Control Study. J Environ Public Health. 2018;2018.

17. World Health Organization Nutrition. Use and interpretation of haemoglobin concentrations for assessing anaemia status in individuals and populations. 2018; https://www.who.int/nutrition/callforauthors_ anaemia_status/en/. Accessed September 20, 2019. 
18. Austin PC, Goel V, van Walraven C. An introduction to multilevel regression models. Can J Public Health. 2001;92(2):150-154. doi:10.1007/BF03404950

19. World Health Organization. Global Health Observatory (GHO) data. Causes of child mortality. https://www.who.int/gho/child_health/mor tality/causes/en/. Accessed February 5, 2019.

20. WHO. Sustainable Development Goals (Sdgs): Goal 3. Target 3.2: By 2030, End Preventable Deaths of Newborns and Children Under 5 Years of Age. World Health Organization; 2016.

21. Central Statistical Agency Addis Ababa and The DHS Program ICF Rockville, Maryland, USA. Ethiopian Demographic and Health Survey 2011. Central Statistical Agency (CSA): Ethiopia; 2012.

22. Centers for disease control and prevention. Children's Environmental Health. 2018; Available from: https://ephtracking.cdc.gov/ showChildEHMain.action. Accessed February 9, 2019.

23. Laflamme M. Hand, foot, and mouth disease. Health Line. 2016;14 (4):308-18.

24. Pongou R, Ezzati M, Salomon JA. Household and community socioeconomic and environmental determinants of child nutritional status in Cameroon. BMC Public Health. 2006;6(98):98.

25. Simon A. Evolution of the immune system in humans from infancy to old age. Proc Biol Sci 2015;282(1821):20143085.

26. Kandala NB, Emina JB, Nzita PD, Cappuccio FP. Diarrhoea, acute respiratory infection, and fever among children in the Democratic Republic of Congo. Soc Sci Med. 2009;68(2009):1728-1736. doi:10.1016/j.socscimed.2009.02.004

27. Choube A, Kumar B, Mahmood SE, Srivastava A. Risk factors contributing to respiratory infection in under five age group children. Int J Med Sci Public Health. 2014;3(11):1385-1388.

28. Sea G-F. Preterm birth affects the risk of developing immunemediated diseases. Front Immunol. 2017;8(1):1266

29. Melville JM. The immune consequences of preterm birth. Front Neurosci. 2013;7(79). doi:10.3389/fnins.2013.00079

30. Tea S. Risk factors for respiratory syncytial virus associated with acute lower respiratory infection in children under five years: systematic review and meta-analysis. J Glob Health. 2015;5(2).
31. Christou A, Dibley MJ. Beyond counting stillbirths to understanding their determinants in low- and middle-income countries: a systematic assessment of stillbirth data availability in household surveys. Trop Med Int Health. 2017;22(3):294-311. doi:10.1111/tmi.12828

32. Alam DS, Fuchs G, Ara G, et al. Low birth weight is associated with altered immune function in rural Bangladeshi children: a birth cohort study. Am J Clin Nutr. 2007;85(3):845-852. doi:10.1093/ ajen/85.3.845

33. Mekuriaw Alemayehu KA, Hardeep R, et al. Household fuel use and acute respiratory infections in children under five years of age in gondar city of Ethiopia. J Environ Earth Sci. 2014;4 (7):77-85

34. Janjua NZ, Dharma VK, Sathiakumar N, Khan MI. Use of biomass fuel and acute respiratory infections in rural Pakistan. Public Health. 2012;126(10):855-862. doi:10.1016/j.puhe.2012.06.012

35. Hea S. Association of biomass fuel use with acute respiratory infections among under- five children in a slum urban of Addis Ababa, Ethiopia. BMC Public Health. 2014;14. doi:10.1186/14712458-14-1122

36. Nuruzzaman Khan MD, Islam MM, Islam MR, Rahman MM. Household air pollution from cooking and risk of adverse health and birth outcomes in Bangladesh: a nationwide populationbased study. Enviro Health. 2017;16:57.

37. Jackson S, Mathews KH, Pulanic D, et al. Risk factors for severe acute lower respiratory infections in children: a systematic review and meta-analysis. Croat Med J. 2013;54(2):110-121. doi:10.3325/ cmj.2013.54.110

38. Stream JO, Luks AM, Grissom CK, Stream JOea. Lung disease at high altitude Expert review. Expert Rev Respir Med. 2009;3(6):635650. doi:10.1586/ers.09.51

39. Cogo A, Fischer R, Schoene R. Respiratory Diseases and High Altitude. High Alt Med Biol. 2004;5(4):435-444. doi:10.1089/ham. 2004.5.435

40. Aea H. Altitude and COPD prevalence: analysis of the PREPOCOLPLATINO-BOLD-EPI-SCAN study. Respir Res. 2017;18(1):162.
International Journal of General Medicine

\section{Publish your work in this journal}

The International Journal of General Medicine is an international, peer-reviewed open-access journal that focuses on general and internal medicine, pathogenesis, epidemiology, diagnosis, monitoring and treatment protocols. The journal is characterized by the rapid reporting of reviews, original research and clinical studies across all disease areas. The manuscript management system is completely online and includes a very quick and fair peer-review system, which is all easy to use. Visit http://www.dovepress.com/ testimonials.php to read real quotes from published authors. 